\title{
Effect of Educational Programme for recently diagnosed Gestational Diabetic Women on their
} Knowledge and clinical outcomes

\author{
Abeer Mostafa Abd Elmoaty ${ }^{(1)}$ Ekbal Abd el rheem Emam ${ }^{(2)}$, Hoda Abd el aziam Mohmed ${ }^{(3)}$
}

1 B.Sc. in Nursing

2 Professor of Women Health and Obstetric Nursing, Faculty of Nursing, Minia University

3 Professor of Women Health and Obstetric Nursing, Faculty of Nursing, Minia University

\begin{abstract}
Background: Gestational diabetes is defined as any degree of glucose intolerance with onset or first recognition during pregnancy; and it affects $11 \%$ of all pregnancies. Aim of this study is to : Evaluate the effect of educational programme for recently diagnosed Gestational Diabetic Women on their Knowledge and clinical outcome.Research Design: Quasi- experimental research design (One group pre-test, post-test).Subject: purposive sampleof (74) recruited pregnant women from Minia university hospital for maternity and child at antenatal care Department. Tools of data collection:three tools used as; self-administered Questionnaire,knowledge assessment,and clinical outcome assessment.Results: the majority of gestational diabetic women $(93.2 \%, 97.3 \%)$ had good knowledge in immediate and Post 3 months respectively as compared in pre-educational program $(23.0 \%)$ with highly statistically significance differences in which $(\mathrm{P}=0.000$.); and there were highly statistically significance differences between pre and post educational program among gestational diabetes women regarding their clinical outcome random blood glucose and amniotic fluid amount in which $(\mathrm{P}=0.002,0.001)$.Conclusion: study of educational programme is an effective method for improving women knowledge regarding gestational diabetes. Current study revealed that the gestational diabetic women had higher level of knowledge scores as well as improvement of clinical outcomes (random blood glucose and BMI) post-test significantly after education program as compared to their values at pretest.Recommendation: Providing educational program for recently diagnosed gestational diabetic women about proper management of GDM. Applying Counseling tips in gestational diabetic women discharge teaching plan to maintain healthy life style and maximum glycemic control prior to a future conception.
\end{abstract}

Keywards: Gestational diabetes mellitus, Maternal and Neonatal consequences, Clinical outcome

\begin{abstract}
Introduction
Gestational diabetes mellitus (GDM) is described as a glucose intolerance which is first diagnosed in pregnancy. Gestational diabetes mellitus is diagnosed in second and third trimesters of pregnancy, GDM has emerged as a global public health problem even though symptomatic in its specialized medical course, and the oral glucose tolerance test is recommended for screening of GDM between the 24thand 28thweek of pregnancy, but for high risk pregnancy the screening should be conducted earlier in pregnancy (1).

Gestational diabetes mellitus (GDM) is a type of diabetes that affects pregnant women during the second and third trimester due to insulin resistance that has resulted from hormone production by the placenta. There are several factors have shown to have a role in developing of GDM. The most common risk factors include previous personal and family history of GDM, history of the macrocosmic baby, unexplained stillbirths, and family history of type 2 of diabetes. In-between pregnancy, weight gain is considered one of the most common modifiable risk factor for GDM. Advanced maternal age and cigarette smoking are also risk factors for GDM(2).

(GDM) has been estimated that $75-90 \%$ of cases of high blood glucose during pregnancy are GDM. A major part of GDM management involves educating patients about diet, exercise, self-monitoring, and insulin treatment to decrease its morbidity and mortality(3). Knowledge and awareness about this chronic disease will be translated to an increase in selfcare as a result of early diagnosis and treatment, which ultimately will contribute to complication reduction. Undiagnosed or inadequately treated GDM can lead to significant maternal and fetal complications. Moreover, women with GDM and their offspring's are at increased risk of developing type 2 diabetes later in life(4).
\end{abstract}

$P$ a g e | 149
Gestational diabetes mellitus knowledge allows patients and those at risk to undertake early interference and thus prevent many complications by making simple lifestyle changes that include an increase in physical activity and diet control(5).Thus, pregnant women need to have a good knowledge on GDM and the lifestyle interventions that manage or reduce GDM and future T2DM; in which this education will improve pregnant women Knowledgeand clinical outcome (6).

\section{Significance of the study}

The prevalence of gestational diabetes mellitus in the worldwide has been increased. According to the Centers for Disease Control and Prevention (2014), the incidence of gestational diabetes varies by states and by race/ethnicity. The incidence of gestational diabetes mellitus increased from $8.1 \%$ to $9.2 \%$ between 2009 and 2010 . Accordingly, the impact is felt on the amount of money spent on diagnoses and treatment as well as disability and research. Subsequently, the risk of gestational diabetes mellitus in mothers and the neonate is the increased risk of developing Type 2 diabetes as well as excessive birth weight of the infant [7]. Some studies have established that GDM may increase the chance for birth defects. Other studies have linked autism, schizophrenia, depression, and obesity gestational diabetes mellitus complication in later life there is an increased risk for both mother and the neonate to have urinary tract infection, preeclampsia, neonatal hypoglycemia, jaundice and high cesarean sections as a result of these complications [8].

According to the study done by El Sagheer and Hamdi (2018) ${ }^{(9)}$ who assessed the prevalence of GDM in ElMinia city, Egypt by using the Diabetes in Pregnancy Study Group India (DIPSI) in comparison to the International Association of the Diabetes and Pregnancy Study Groups 
(IADPSG) criteria, found that the risk factors for GDM in this locality reported that $156 \backslash \mathrm{GDM}$ prevalence in El-Minia city was $8.86 \%$ by DIPSbI versus $7.43 \%$ by IADPSG.

Moreover, mothers with prior knowledge of GDM preventive measures are shown to had low risk of susceptibility of diagnoses; thereby reducing the possibility of prenatal complications. The importance of GDM knowledge among women is vital in reducing birth complications and outcomes. This is because mothers are the most vital component to reducing health complications and birth outcomes through gestational diabetes mellitus awareness(10).

\section{Aim of the study is to:}

Evaluate the Effect of Educational Programme for recently diagnosed Gestational Diabetic Women on their Knowledge and clinical outcome.

\section{Research hypothesis}

1) 1-Post-test knowledge score will be significantly higher than pre -test knowledge scors among recently diagnosed Gestational Diabetic Women

2) 2-There will be significant association between knowledge scores of pregnant women and their clinical outcome.

3) 3-There will be significant association between pretest knowledge scores of pregnant women and their demographic characteristics regarding gestational diabetes.

\section{Subjects and Methods \\ Research Design}

Quasi experimental research design (one group pretest and post-test)was utilized to fulfill the aim of this study.

\section{Research Setting:}

This study was conducted at Minia university hospital for maternity and child at antenatal care Department.

\section{Subjects:}

Purposive sample was utilized in this research. The sample size was 74 pregnant women according to the following formula

$$
\begin{gathered}
\mathbf{N}=\frac{\mathbf{t}^{2} \mathbf{x}(\mathbf{1}-\mathbf{p})}{\mathbf{m}^{2}} \\
\mathbf{N}=\frac{(\mathbf{1 . 9 6})^{2} \mathbf{0 . 0 5}(\mathbf{1 - 0 . 0 5})}{\mathbf{0 . 0 5}^{2}} \\
\mathrm{~N}=74 \text { pregnant }
\end{gathered}
$$

\section{Inclusion criteria}

- Pregnant women (first or second trimester)

- Recently diagnosed Gestational Diabetes Pregnant Women

\section{Exclusion criteria}

- Women have any medical problems

- Women have past history of gestational diabetes mellitus.

- Women during third trimester.

\section{Data Collection Tools:}

Tools of data collection were developed by the researcher after extensive review of literature and similar studies conducted elsewhere. After that the developed tools are revised by 5 panels of nursing professor in obstetrical and gynecological nursing field. The data collection tools were as follows:

\section{Tool (I):}

A Self-administrative questionnaire:

It was used to assess Socio-demographic characteristics and obstetric history of the subjects: such as(age, marital status, residences, educational level, and income). Past obstetric history as (No. of gravidity, No. of parity, No. of live births, have a premature baby and Current Gestationalage, source of women knowledge, in addition to mother telephone no).

\section{Tool (II):}

The Knowledge assessment questionnaire (pre/post-test) it was developed by the researcher after extensive literature review ${ }^{(11-14)}$; and it included 34 multiple choice questions to assessknowledge regarding to GD and its management

The questionnaire had 7 sections: the first section had questions about insulin, diabetes, and gestational diabetes definitions; the second Section had questions about factors that increase the risk of developing diabetes in this group of questions women asked what effect smoking, stress, being over weight, diet high in fat and sugar and high blood pressure have on the risk of developing GDM; the third section had questions about signs and symptoms of Gestational Diabetes; the fourth section had questions about consequences of GDM related to maternal and fetus; the fifth section had questions about management of GDM in this group of questions women asked what initial treatment for GD,important ofPhysical activity,Self- monitoring of blood glucose, insulin dose, sites of insulin, type of insulin, storage of insulin and insulin syringe; the sixth section had questions about normal and abnormal level of plasma glucose; and the seventh sectionhad questions about the follow up and postpartum care.

\section{Scoring System:}

The women's answers related to knowledge were scores and calculated; each correct answer was given a score of one and wrong answers a score of zero. It was assigned for each answer representation (correct, incorrect) respectively. Total knowledge score classified as (poor knowledge scored $<50 \%$ ( $<17$ score), average knowledge 50\%- 75\%(17-<25.5) and good knowledge scored $\geq 75 \%$ (25.5 or above).

\section{Tool (III):}

\section{Clinical outcomes assessment tool:}

This tool was used to collect data about selected investigations such as: random blood sugar test, body mass index, amniotic fluid amount, and fetal weight.Clinical outcomes assessment tool were measured two timespreprogramimplementationand post 3 months of the program.

\section{As regarding to Random blood sugar test:}

- Normal level considered when Initial Fasting level: $92 \mathrm{mg} / \mathrm{dL}(5.1 \mathrm{mmol} / \mathrm{L})$,Fasting after 1 hour: 180 $\mathrm{mg} / \mathrm{dL}(10.0 \mathrm{mmol} / \mathrm{L})$,Fasting after 2 hours: 153 $\mathrm{mg} / \mathrm{dL}(8.5 \mathrm{mmol} / \mathrm{L})$

- While Hyperglycemia considered when initial Fasting level: $>92 \mathrm{mg} / \mathrm{dL}(5.1 \mathrm{mmol} / \mathrm{L})$, Fasting after 
1 hour: $>180 \mathrm{mg} / \mathrm{dL}(10.0 \mathrm{mmol} / \mathrm{L})$,Fasting after 2 hours: $>153 \mathrm{mg} / \mathrm{dL}(8.5 \mathrm{mmol} / \mathrm{L})^{(15)}$.

- As regarding to Body mass index: it was calculated by using the following formula

- $\quad$ BMI = weight $(\mathrm{kg}) /[\text { height }(\mathrm{m})]^{2}$

- After calculation body mass index and subtract the standard weight gain during pregnancy according to World Health Organization. BMI (2012) classification was as the follow: if the women under weight (BMI less than18.5), if the women healthy weight (BMI 18.5-24.9), and if the women obese (BMI 30 and above).

\section{As regarding to measurements of Amniotic fluid amount:}

* There are two ultrasound measurements used to measure the amniotic fluid levels that surrounding the baby during pregnancy done by physician:

○ Amniotic Fluid Index (AFI): this method uses the sum of four of the deepest vertical pocket of fluid. The normal range for the AFI is $5-25 \mathrm{cms}$.

○ Single Deepest Pocket (SDP): this method measures the depth of the largest visible pocket of fluid surrounding the fetus. The normal range for maximum pool is $2-8 \mathrm{cms}$.

* After measured amount of amniotic fluid the finding divided into

- Small amount (oligo-hydramnios) when the AFI (amniotic fluid index) measurement is below 5 or 6 , and the SDP (single deepest pocket) is less than $2 \mathrm{~cm}$.

- Normal amount: AFI is $5-25 \mathrm{cms} / \mathrm{SDP}$ is 2$8 \mathrm{cms}$

- Large amount (polyhydramnios) when the AFI (amniotic fluid index) measurement is greater than $25 \mathrm{~cm}$, and the SDP (single deepest pocket) is greater than $8 \mathrm{~cm}^{(16)}$.

\section{Assessment of fetal weight through:}

After delivery the researcher asked the women through a telephone call about the weight of their baby; and according to the mother report the fetal weight was interpreted as the follows:

- Low birth weight (below $2500 \mathrm{~g}$ ).

- Normal birth weight (between $2500 \mathrm{~g}$ and $4000 \mathrm{~g}$ ).

- High birth weight (above $4000 \mathrm{~g})^{(2)}$.

\section{Validity and Reliability:}

To establish validity, the tools were submitted to panel of 5 experts of Nursing Professorin Obstetrics and Gynecological Nursing field, who reviewed the instruments for clarity, relevance, comprehensiveness, understanding, applicability and easiness. To establish reliability of the tools the Cronbach'salpha method was used to check the stability of the internal consistency of instruments; and Cronbach's alpha for tool II was $(\alpha=0.85)$.

\section{Pilot Study:}

A pilot study was conducted on ( 7 women) $10 \%$ of antenatal mothers at the previous mentioned setting to assess the current study tools for its clarity, validity and time required to be applied and to evaluate the study process. According to the results of the pilot, all required and necessary modifications were done and the women who were tested in the pilot study not included in the study subjects.

\section{Data collection Procedure:}

The current study was achieved through three phases; assessment phase (pre-test), implementation (conducting education program), and follow up and evaluation phase (post -test).

\section{1- Assessment phase (pre-test)}

- During assessment phase; the researcher held the first meeting with women to introduce herselfand given an explanation about the nature and purpose, duration, and activities of the study. They were informed that participation in this study was voluntary and they had the right to withdraw at any time, oral approval of women to share in the study was achieved.

- After obtaining the acceptance from women to participate in the current study, the researcher provided an overview and clarification about the assessment tool questions then the self-administered questionnaire was distributed to each woman to assess data related to socio-demographic data and obstetric history, the questionnaire took about 15 minute to be completed.

- Then the researcherdistributed pretest questionnaire to assess women knowledge regarding to GD and its management.

2- Implementation phase (conducting education program)

- After assessing women knowledge regarding to GD by knowledge assessment questionnaire; the researcher collected the sample through two days per week from the beginning of the study. The study was carried out in the period from December2018 through June, 2019. The researcher attended to antenatal care Department at 9:00 a.m., to 1:00 p.m.; and face to face interview was done.

- The total sample (74) was divided into small group; each group had from 5 to 7 pregnant women. Then the sessions were done as around two sessions per day for each small group. Each session lasted for about 35 to 45 minute.

- During implementation of health education program, the participated woman in the study received the knowledge about GDM and its management through using face to face method to achieve the proposed goal of the study. The researcher allows women to ask any questions during the discussion, and provide clear explanation for participated women to reach high level of understanding. During these sessions the researcher used illustrations, examples of objects, booklet and brochure; as well as the session was based on discussion which was emphasized on improving women's knowledge. Also, there was further 15 minute was assigned at the end of the discussion for more questions from participated womenand obtains the feedback to ensure that the women got maximum benefits.

- The entire study subject received booklet which includes knowledge related to gestational diabetes such as definition, causes, sign and symptoms, risk factor and how to manage it. 


\section{3- Evaluation phase (post -test)}

Three time of evaluation were done for each woman:

- First time of evaluation (pre-test) was done before implementation of the educational program as a baseline data using tool (I); tool (II)to assess Knowledge of the mother; and tool (III) to perform clinical measures (random blood sugar, body mass index of the mother, amniotic fluid amount, andfetal weight).

- Second time of evaluation (immediate post-test) done immediately after implementation of the guideline using tool (II) to assess Knowledge of the mother.

- Third time of evaluation(post-test) done after 3 months of the guideline using tool (II) to asses knowledge of the mother and tool (III) to perform clinical measures.

- After delivery the researcher asked the women through telephone call about the weight of their baby.

- The effect of health education program was done through comparing between pre-test and post-test that were conducted immediately and after 3 months of educational program implementation to assess their knowledge regarding GD and its management.

\section{Supportive material (Health education guideline):}

It was designed to enhance the women knowledge regarding GD and itsmanagement;it was designed by the researcher in the form of handout (booklet) using simple Arabic language and different illustrative picture in order to facilitate the understandingof its content.

\section{Administrative design:}

An official written approval letter clarifying the purpose of the present study was approved from the dean of the Faculty of Nursing, as well as the Director of Minia university hospital for maternity and child as an approval for data collection to conduct this study.

\section{Ethical consideration:}

An official permission (oral consent) to carry out the study was obtained from women that are willing to participate in the study, after explaining the importance, aim, nature and purpose of the study. All participants have the right to refuse to participate and or withdraw from the study without any rational any time. The privacywas considered during collection of data; and no health hazards were present. Participants were assured that all their data are highly confidential;in addition anonymity was assured through assigning a number for each nurse instead of names to protect their privacy.

\section{Statistical Design:}

The collected data were organized, categorized and analyzed using statistical package of social science (SPSS) version 20 and excel for figures. Data were presented using descriptive statistics in the form of frequencies and percentages for qualitative variables, and means and standard deviations for quantitative variables. Statistical significance was considered when $\mathrm{P}$ value $\leq 0.05$, high Statistical significance was considered when $\mathrm{P}$ value $\leq 0.001$; no statistical significance was considered when $P$ value $\geq 0.05$. Fisher exact test was used to detect the relation between women knowledge based on their selected socio-demographic characteristics and the relation between women knowledge and their clinical outcomes.

\section{Results}

The results of this study are presented under the following heading: Socio-demographic characteristics, knowledgeabout gestational diabetes, clinical outcomes ofgestational diabetes, relationship between women knowledge regarding gestational diabetes and their selected socio demographic characteristics, relationship between women knowledge regarding gestational diabetes and their clinical outcomes pre-and post-educationalprogram.

Table (1): Percentage distribution of gestational diabetic women related to their Socio-demographic characteristics $(\mathrm{n}=74)$.

\begin{tabular}{|c|c|c|}
\hline Socio-demographic characteristics & No. & $\%$ \\
\hline \multicolumn{3}{|l|}{ Age/ years } \\
\hline - $\quad<25$ & 29 & 39.2 \\
\hline $25-35$ & 25 & 33.8 \\
\hline $35-<45$ & 20 & 27.0 \\
\hline \multicolumn{3}{|l|}{ Residence } \\
\hline - $\quad$ Rural & 53 & 71.6 \\
\hline - $\quad$ Urban & 21 & 28.4 \\
\hline \multicolumn{3}{|l|}{ Educational level } \\
\hline - $\quad$ Illiterate & 8 & 10.8 \\
\hline Read and write & 17 & 23.0 \\
\hline Primary & 6 & 8.1 \\
\hline Secondary & 13 & 17.6 \\
\hline - $\quad$ University & 30 & 40.5 \\
\hline \multicolumn{3}{|l|}{ Income / L.E } \\
\hline - $\quad<1000$ & 26 & 35.1 \\
\hline $1000-<1500$ & 22 & 29.7 \\
\hline $1500-<2000$ & 18 & 24.3 \\
\hline$>2000$ & 8 & 10.8 \\
\hline
\end{tabular}

Table (1) shows that, there was more than one quarter (39.2\%) of gestational diabetic women aged less than 25 years, $(71.6 \%)$ of them lives in rural area, $(40.5 \%)$ of them had high educational level, and $(35.1 \%)$ of them their income was less than 1000 L.E. 


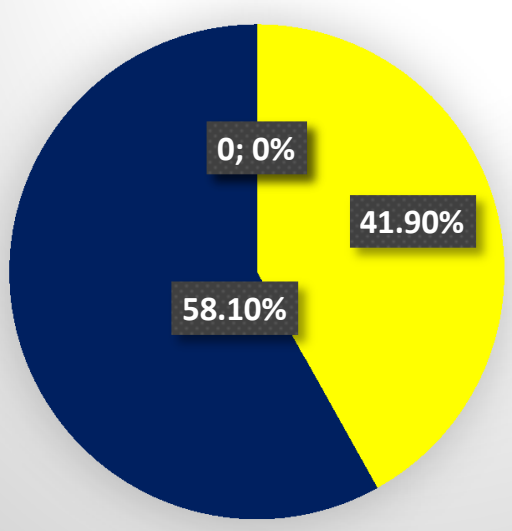

Figure (1): Percentage distribution regarding current gestational age of studied sample in pre-educational instructions $(\mathrm{n}=$ 74).

Figure (1): illustrates that, more than half(58.1\%) of gestational diabetic women was in 24- 27 weeks of gestational age and $(41.9 \%)$ of them was in $32-35$ weeks of gestational age pre-educational instructions.

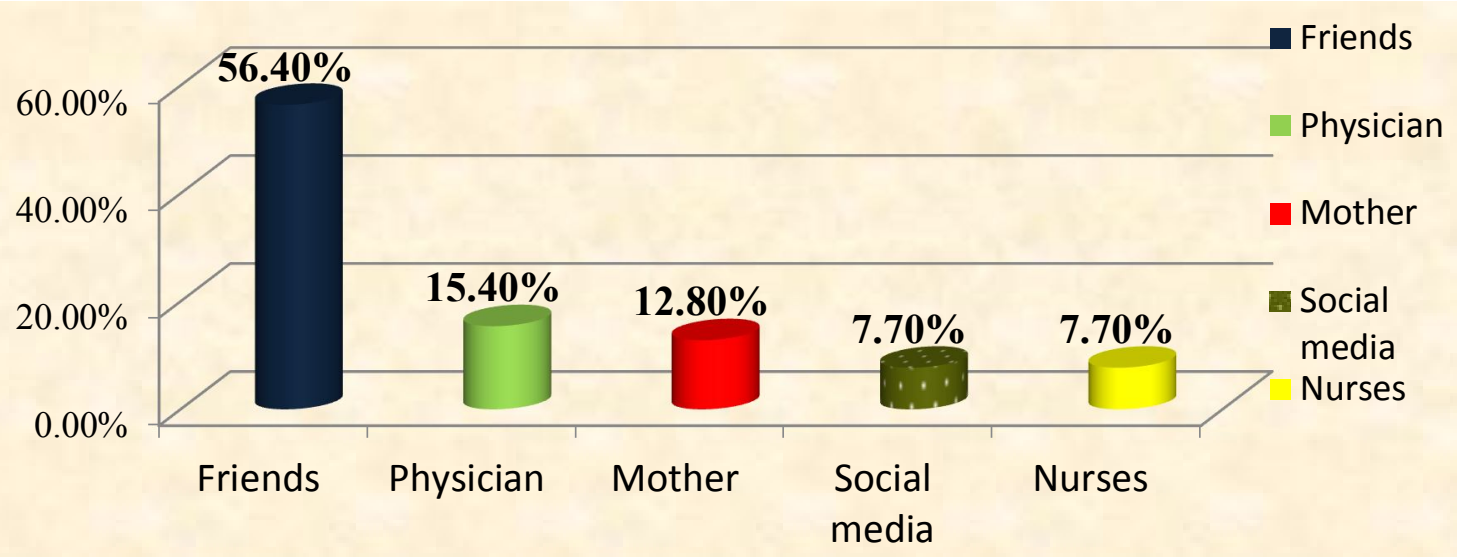

Figure (2): Percentage distribution gestational diabetic women regarding their source of knowledge about gestational diabetes $(n=74)$

Figure (2): Shows that, more than half (56.4\%) of gestational diabetic women their source of knowledge about gestational diabetes was their friends and only 7.7 of them their source of knowledge was social media and nurse.

Table (2): Percentage distribution of gestational diabetic women regarding their correct knowledge about laboratory investigations of gestational diabetes $(n=74)$.

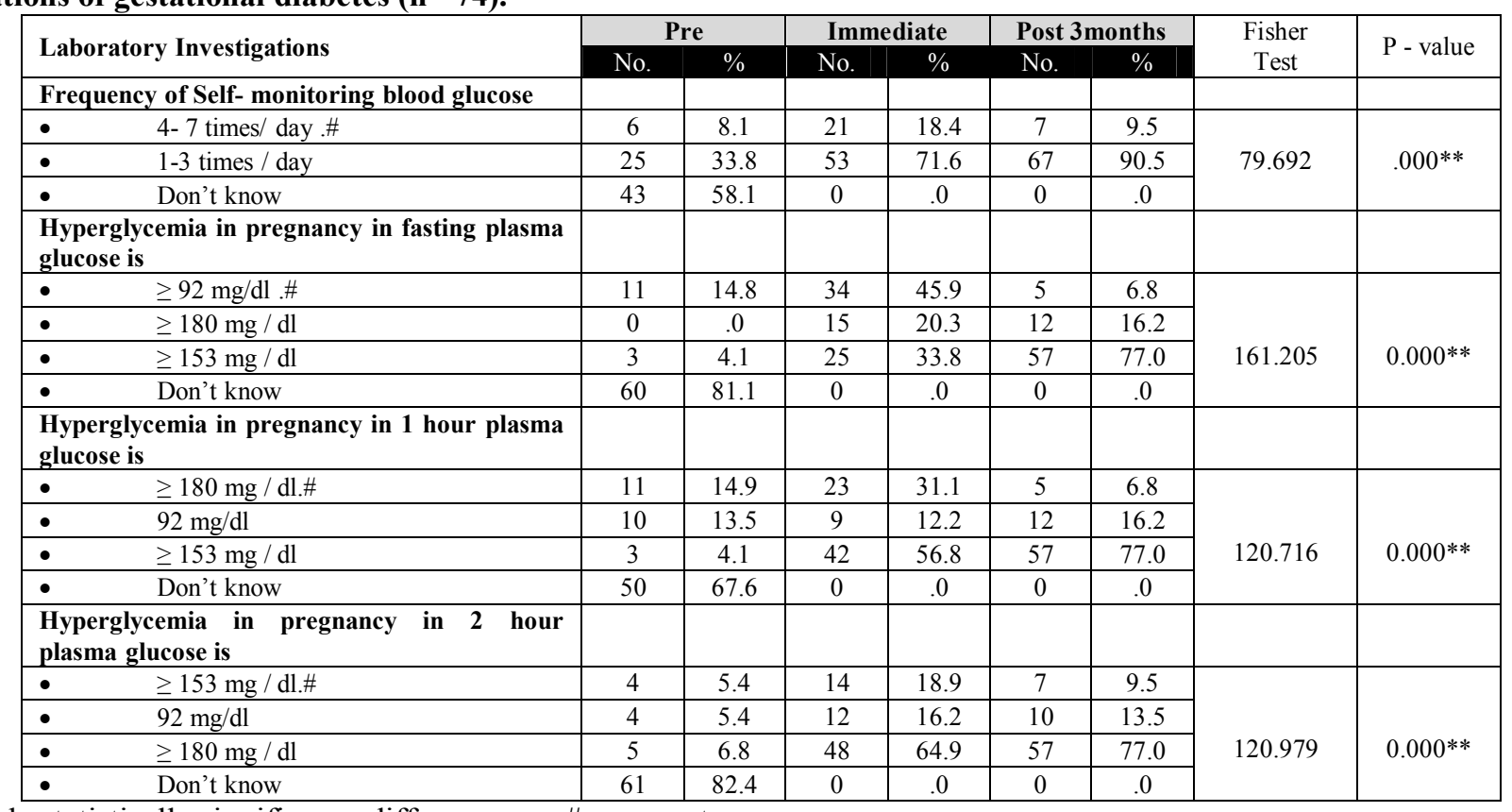

$* *=$ highly statistically significance differences $\quad \#=$ correct answer 


\section{Minia Scientific Nursing Journal (Print) (ISSN 2537-012X) Vol. (6) No. (1) December 2019}

Table (2) shows that $58.1 \%, 81.1 \%, 67.6 \%$, and 82.4 of gestational diabetic women have no knowledge regarding laboratory investigations in pre-educational program; and decreased to $0 \%, 0 \%, 0 \%$, and $0 \%$ in immediate and post 3 months educational program respectively with highly statistically significance differences between pre- immediate - post educational program $(\mathrm{P}=0.000)$. Table (3): Percentage distribution of gestational diabetic women regarding total knowledge score about gestational diabetes $(n=74)$.

\begin{tabular}{|c|c|c|c|c|c|c|c|c|}
\hline \multirow[b]{2}{*}{ Knowledge levels } & \multicolumn{2}{|c|}{ Pre } & \multicolumn{2}{|c|}{ Immediate } & \multicolumn{2}{|c|}{ Post 3 months } & \multirow{2}{*}{ Fisher } & \multirow{2}{*}{$P$ - value } \\
\hline & No. & $\%$ & No & $\%$ & No. & $\%$ & & \\
\hline Poor & 24 & 32.4 & 0 & 0.0 & 0 & 0.0 & \multirow{3}{*}{129.874} & \multirow{3}{*}{$.000 * *$} \\
\hline Average & 33 & 44.6 & 5 & 6.8 & 2 & 2.7 & & \\
\hline Good & 17 & 23.0 & 69 & 93.2 & 72 & 97.3 & & \\
\hline
\end{tabular}

** = highly statistically significance differences

Table (3): showes that the majority of gestational diabetic women $(93.2 \%, 97.3 \%)$ had good knowledge in immediate and post 3 months respectively as compared with women knowledge in pre-educational programe(23.0\%) with highly statistically significance differences $(\mathrm{P}=0.000)$.

Table (4): Percentage distribution of gestational diabetic women regarding their clinical outcomes pre and post 3 months of educational program $(n=74)$

\begin{tabular}{|c|c|c|c|c|c|c|}
\hline \multirow{3}{*}{ Clinical outcomes } & \multicolumn{4}{|c|}{ Educational program } & \multirow{3}{*}{$\mathrm{X}^{2}$} & \multirow{3}{*}{$\mathrm{P}$-value } \\
\hline & \multicolumn{2}{|c|}{ Pre } & \multicolumn{2}{|c|}{ Post } & & \\
\hline & No. & $\%$ & No. & $\%$ & & \\
\hline \multicolumn{7}{|l|}{ Random blood glucose level } \\
\hline $\begin{array}{l} \\
\end{array} \quad$ Normal level & 52 & 70.3 & 67 & 90.5 & \multirow[b]{2}{*}{9.649} & \multirow[b]{2}{*}{$0.002 * *$} \\
\hline Hyperglycemia & 22 & 29.7 & 7 & 9.5 & & \\
\hline \multicolumn{7}{|l|}{ BMI } \\
\hline Under weight & 8 & 10.8 & 1 & 1.4 & \multirow{3}{*}{6.315} & \multirow{3}{*}{$0.04 *$} \\
\hline Normal weight & 52 & 70.3 & 61 & 82.4 & & \\
\hline - $\quad$ Obese & 14 & 18.9 & 12 & 16.2 & & \\
\hline \multicolumn{7}{|l|}{ Amniotic fluid amount } \\
\hline - $\quad$ Small amount & 1 & 1.4 & 0 & .0 & \multirow{3}{*}{13.546} & \multirow{3}{*}{$0.001 * *$} \\
\hline Normal & 38 & 51.4 & 59 & 79.7 & & \\
\hline Large amount & 35 & 47.3 & 15 & 20.3 & & \\
\hline \multicolumn{7}{|l|}{ Fetal weight } \\
\hline - $\quad$ Low birth weigh & 14 & 18.9 & 9 & 12.2 & \multirow{3}{*}{5.124} & \multirow{3}{*}{$0.05^{*}$} \\
\hline Normal birth weight & 36 & 48.6 & 52 & 70.3 & & \\
\hline High birth weight & 24 & 32.4 & 13 & 17.5 & & \\
\hline
\end{tabular}

$* *=$ highly statistically significance differences $*=$ statistically significance differences

Table (4): indicates that, there were highly statistically significance differences between pre and post 3 months educational program among gestational diabetes women regarding their clinical outcome which $29.7 \%$ of them had hyperglycemia vs. $9.5 \%$ of them post 3 months $(\mathrm{P}=0.002)$. As regardingamniotic fluid amount there was $(47.3 \%)$ of women had large amount in pre educational program and decreased to $(20.3 \%)$ of them had large amniotic fluids in post educational program with statistical significant difference $(\mathrm{P}=0.001)$.

Also, there was statistical significance differences between pre and post educational program among gestational diabetic women regarding their body mass index which $(70.3 \%)$ of them was normal pre educational and increased to $(82.4 \%)$ of them post educational $(\mathrm{P}=0.04)$. In addition to fetal birth weight there was $(48.6 \%)$ of them normal in pre educationalprogramand increased to $(70.3 \%)$ in post educational programwith statistical significance difference $(\mathrm{P}=0.05)$.

Table (5): Relationship between women knowledge regarding gestational diabetes and their selected socio demographic characteristics $n=74)$.

\begin{tabular}{|c|c|c|c|c|c|c|c|c|c|}
\hline \multirow{3}{*}{\multicolumn{2}{|c|}{ Socio demographic characteristics }} & \multicolumn{6}{|c|}{ Women knowledge } & \multirow{3}{*}{$\mathrm{X}^{2}$} & \multirow{3}{*}{$\begin{array}{c}\mathrm{P}- \\
\text { value }\end{array}$} \\
\hline & & \multicolumn{2}{|c|}{ Poor } & \multicolumn{2}{|c|}{ Average } & \multicolumn{2}{|c|}{ Good } & & \\
\hline & & No. & $\%$ & No. & $\%$ & No. & $\%$ & & \\
\hline \multicolumn{10}{|c|}{ Age/ years } \\
\hline - & $<25$ & 10 & 41.7 & 14 & 42.4 & 5 & 29.4 & \multirow{3}{*}{8.564} & \multirow{3}{*}{$.05 *$} \\
\hline - & $25-35$ & 8 & 33.3 & 14 & 42.4 & 3 & 17.6 & & \\
\hline$\bullet$ & $35-<45$ & 6 & 25.0 & 5 & 15.2 & 9 & 52.9 & & \\
\hline \multicolumn{10}{|c|}{ Residence } \\
\hline$\cdot$ & Rural & 19 & 79.2 & 24 & 72.7 & 10 & 58.8 & \multirow{2}{*}{2.062} & \multirow{2}{*}{.357} \\
\hline - & Urban & 5 & 20.8 & 9 & 27.3 & 7 & 41.2 & & \\
\hline \multicolumn{10}{|c|}{ Educational level } \\
\hline - & Illiterate & 2 & 8.3 & 2 & 6.1 & 4 & 23.5 & \multirow{5}{*}{15.648} & \multirow{5}{*}{$.05 *$} \\
\hline - & Read and write & 5 & 20.8 & 12 & 36.4 & 0 & .0 & & \\
\hline - & Primary & 2 & 8.3 & 3 & 9.1 & 1 & 5.9 & & \\
\hline - & Secondary & 5 & 20.8 & 7 & 21.2 & 1 & 5.9 & & \\
\hline - & University & 10 & 41.7 & 9 & 27.3 & 11 & 64.7 & & \\
\hline \multicolumn{10}{|c|}{ Income } \\
\hline - & $<1000$ & 8 & 33.3 & 14 & 42.4 & 4 & 23.5 & \multirow{4}{*}{4.723} & \multirow{4}{*}{.580} \\
\hline - & $1000-<1500$ & 8 & 33.3 & 9 & 27.3 & 5 & 29.4 & & \\
\hline & $1500-<2000$ & 6 & 25.0 & 8 & 24.2 & 4 & 23.5 & & \\
\hline - & $>2000$ & 2 & 8.3 & 2 & 6.1 & 4 & 23.5 & & \\
\hline
\end{tabular}

$\mathrm{NS}=$ Not statistically significance differences 
Table (5): presents that there were statistically significance relationship between total knowledge scores of gestational diabetic women pre-educational program and their age in which $(\mathrm{P}=0.05)$, knowledge of gestational diabetes mothers pre educational program and their educational levels in which $\mathrm{P}-$ value $\leq 05$.

Table (6): Relationship betweenwomen knowledge regarding gestational diabetes and their clinical outcomes pre-and posteducationalprogram $(n=74)$

\begin{tabular}{|c|c|c|c|c|c|c|c|c|c|c|}
\hline \multirow{4}{*}{ Clinical outcomes } & \multicolumn{10}{|c|}{ Women knowledge regarding gestational diabetes } \\
\hline & \multicolumn{5}{|c|}{ Pre } & \multicolumn{5}{|c|}{ Post 3 months } \\
\hline & \multicolumn{2}{|c|}{$\begin{array}{l}\text { Poor } \\
(24)\end{array}$} & \multicolumn{2}{|c|}{$\begin{array}{c}\text { Average } \\
\text { (33) }\end{array}$} & \multicolumn{2}{|c|}{$\begin{array}{c}\text { Good } \\
(17)\end{array}$} & \multicolumn{2}{|c|}{$\begin{array}{l}\text { Average } \\
\text { (2) }\end{array}$} & \multicolumn{2}{|c|}{$\begin{array}{c}\text { Good } \\
(72)\end{array}$} \\
\hline & No & $\%$ & No & $\%$ & No & $\%$ & No & $\%$ & No & $\%$ \\
\hline \multicolumn{11}{|l|}{ Random blood glucose level } \\
\hline 1. Normal level & 20 & 83.3 & 24 & 72.7 & 8 & 47.1 & 1 & 50.0 & 66 & 91.7 \\
\hline $2 . \quad$ Hyperglycemia & 4 & 16.7 & 9 & 27.3 & 9 & 52.9 & 1 & 50.0 & 6 & 8.3 \\
\hline$X^{2}-P$ - value & \multicolumn{5}{|c|}{$6.440(.04 *)$} & \multicolumn{5}{|c|}{$3.945(.05 *)$} \\
\hline \multicolumn{11}{|l|}{ BMI } \\
\hline Under weight & 2 & 8.3 & 6 & 18.2 & 0 & .0 & 0 & 0.0 & 1 & 1.4 \\
\hline Normal weight & 2 & 8.3 & 6 & 18.2 & 6 & 35.3 & 1 & 50.0 & 60 & 83.3 \\
\hline $5 . \quad$ Obese & 20 & 83.3 & 21 & 63.6 & 11 & 64.7 & 1 & 50.0 & 11 & 15.3 \\
\hline$X^{2}-P$ - value & \multicolumn{5}{|c|}{$8.337(.080)$} & \multicolumn{5}{|c|}{$7.254(.04 *)$} \\
\hline \multicolumn{11}{|l|}{ Amniotic fluid amount } \\
\hline $6 . \quad$ Small amount & 0 & 0.0 & 1 & 3.0 & 0 & 0.0 & 0 & 0.0 & 0 & 0.0 \\
\hline Normal & 9 & 37.5 & 17 & 51.5 & 12 & 70.6 & 2 & 2.7 & 57 & 77.1 \\
\hline $8 . \quad$ Large amount & 15 & 62.5 & 15 & 45.5 & 5 & 29.4 & 0 & 0.0 & 15 & 20.2 \\
\hline $\mathrm{X}^{2}-\mathrm{P}-$ value & \multicolumn{5}{|c|}{$5.711(.222)$} & \multicolumn{5}{|c|}{$.523(.470)$} \\
\hline \multicolumn{11}{|l|}{ Fetal weight } \\
\hline Low weight & 5 & 20.8 & 6 & 18.2 & 3 & 17.6 & 1 & 50.0 & 8 & 11.1 \\
\hline 9. Normal birth weight & 9 & 37.5 & 20 & 60.6 & 7 & 41.2 & 0 & 0.0 & 52 & 72.2 \\
\hline $10 . \quad$ High birth weight & 10 & 41.7 & 7 & 21.2 & 7 & 41.2 & 1 & 50.0 & 12 & 16.7 \\
\hline$X^{2}-P$ - value & \multicolumn{5}{|c|}{$4.161(0.385)$} & \multicolumn{5}{|c|}{$8.478(0.03 *)$} \\
\hline
\end{tabular}

Table (6) reveals' that, there was statistically significance relationship between knowledge of gestational diabetic women with random blood glucose level in pre and post 3 months $(\mathrm{P}=0.05$, and 0.04 respectively). Also, statistically significance relationshipfound betweenknowledge of gestational diabetic women with their BMI in post 3 months $(\mathrm{P}=0.04)$, in addition between birth weight and their knowledge post 3 months of educational program $(\mathrm{P}=0.03)$.

\section{Discussion:}

Gestational Diabetes Mellitus [GDM] constitutes a major health problem worldwide; and the prevalence of GDM may range from $1 \%$ to $20 \%$ of pregnancies depending on the population studied with the recent recommended diagnostic criteria by the International Association of Diabetes and Pregnancy Study Groups, the prevalence will continue to rise $^{(17)}$.

The present study showed that slightly less than two fifth of pregnant women aged less than 25 years, more than two third of them lives in rural area. This result were confirmed with(El Toony, Khalifa, \& Ghazaly, 2018) ${ }^{(18)}$ who studied"Assessing the effectiveness of an educational program for patients with gestational diabetes in Assiut University" and found that the Mean \pm SD age of the studied participant were $28 \pm 5$ years. Also this result come in accordance with(Bieda, 2009) ${ }^{(19)}$ who studied "Perceptions of risk for the development of type 2 diabetes in African-American women with gestational diabetes" and stated that the average participant's age in years was 25 (Range $=19-40)$.

While, this result were contra indicated with(Dimka, 2015) ${ }^{(20)}$ who studied "Gestational Diabetes Mellitus among College Students, Its Effects on Macrosomia and Risk of Developing Type 2 Diabetes, Monroe College" and mentioned that less than half of the studied sample were from 26:30 yrs. Also(Alharthi, Althobaiti, \& Alswat, 2018) ${ }^{(21)}$ who studied "Gestational Diabetes Mellitus Knowledge Assessment among Saudi Women " and stated that the mean age of the studied sample were $27.8 \pm 7.9$ and the majority of them live in urban setting.

In regarding to educational level; the present study showed that two fifth of them had high educational level. This result come in the line with (Bieda, 2009) ${ }^{(19)}$ who studied
"Perceptions of risk for the development of type 2 diabetes in African-American women with gestational diabetes" and stated that educational level was well represented across the categories from "not graduated from high school" to the completion of "some college". However, this result were contradicted with(Alharthi et al., 2018) ${ }^{(21)}$ who studied " Gestational Diabetes Mellitus Knowledge Assessment among Saudi Women " and mentioned that most of their study participants had bachelor's degrees or higher.

Regarding the income of the studied subjects; the present study showed that more than one third of them had 1000 L.E monthly. This result come inconsistent with(Dimka, 2015) ${ }^{(20)}$ who studied "Gestational Diabetes Mellitus among College Students, Its Effects on Macrosomia and Risk of Developing Type 2 Diabetes, Monroe College" and stated that two third of the participants had an annual income of $\$ 10,000$.

Regarding current gestational age of studied subjectsin pre-educational instructions, it was noted that more than half of pregnant women were in 24- 27 weeks of gestational age pre-educational instructions. This result come in agree with(Bieda, 2009) ${ }^{(19)}$ who studied "Perceptions of risk for the development of type 2 diabetes in African-American women with gestational diabetes" and stated that the mean gestational age at the time of the interviews was 29.3 weeks (Range $=21-39)$. Also,(El Toony et al., 2018) ${ }^{(18)}$ who studied "Assessing the effectiveness of an educational program for patients with gestational diabetes in Assiut University"and confirmed this result in which the mean \pm SD of gestational age (weeks) were $25 \pm 4$. This current study finding may be interpreted due to Gestational diabetes mellitus affects pregnant women during the second and third trimester in which there is insulin resistance that has resulted from hormone production by the placenta. 
The present study illustrated that there were more than half of pregnant women their source of knowledge about gestational diabetes was from their friends and only less than tenth of them their source of knowledge was from social media and nurses. While the result of the study done by(Bieda, 2009) ${ }^{(19)}$ who reported in his study that the majority of the studied sample take their knowledge from family experience, education from health professionals, selfeducation and prior gestational diabetes. This result comes in consistent with (Alharthi et al., 2018) ${ }^{(21)}$ who mentioned that the major sources of GDM awarenesswere reported to be television/radio, neighbors/friends, and family members. Thisfinding of the current study may be due to lack of educational programs regarding the gestational diabetes and the possible complications of GDM that may occur during pregnancy in social media.

Moreover, the present study showed that there was slightly improvement of knowledge regarding laboratory investigation about gestational diabetes. Theresult was explained by(El Toony et al., 2018) ${ }^{(18)}$ who studied "Assessing the effectiveness of an educational program for patients with gestational diabetes in Assiut University"and mentioned that health education plays an important role in increasing the awareness of pregnant women regarding GDM risk and its proper management in order to reduce its burden both for the mother and the fetus. This current study finding may be interpreted due to the women have forgotten the results of the laboratory investigation value because the values appear as numbers and concerning the medical staff more.

The present study showed that less than one quarter of pregnant women had good knowledge level in pre educational program, and increased to be the majority of them $(93.2 \%, 97.3 \%)$ had good knowledge in immediate and post educational program. This come in the line with(ElToony et al., 2018) ${ }^{(18)}$ who reported that most of the questions were answered correctly in the post-test. This result were confirmed by(Mohammed, 2016) ${ }^{(22)}$ who studied "Impact of Designed Teaching Program for Pregnant Women with Gestational Diabetes on Maternal outcomes" and founded that the majority of the sample had inadequate knowledge with score (0-9), whenever $24 \%$ of them had moderate level of knowledge with score (10-18), and 5\% only had adequate knowledge with score (19-27) before attending the program. On the other hand, after attending the program adequate and moderate level of knowledge were $(51 \%$, and $49 \%)$. This current study finding may be interpreted due to the effectiveness of educational program which aid in improving women knowledge regarding gestational diabetes.

The present study clarified that, there were highly statistically significance differences between pre and post educational program among gestational diabetic women regarding their random blood sugar test in which $29.7 \%$ of them had hyperglycemia vs. $9.5 \%$ of them in post-test after 3 months with statistical difference $(\mathrm{P}=0.002)$.also there is statistical significance differences between pre and post educational program among gestational diabetes mothers regarding their body mass index which $70.3 \%$ of them was normal pre educational vs.82.4\% of them post educational with $(\mathrm{P}=0.04)$.

This result was confirmed by(Carolan-Olah \& Sayakhot, 2019) ${ }^{(2)}$ who studied "A randomized controlled trial of a web-based education intervention for women with gestational diabetes mellitus" and stated that the participant knowledge had improved after the intervention program and statistically significant differences were reported between intervention and control groups in maternal weight and glycaemia post-intervention $(\mathrm{P}<0.05)$.

In regarding to birth weight; the present study showed that near to three quarter of infant was within the normal birth weight and few of them was macrosomic baby. This result were confirmed by(Carolan-Olah \& Sayakhot, 2019) ${ }^{(2)}$ who found that the majority of women in both groups had infants with normal birth weight (between $2500 \mathrm{~g}$ and $4000 \mathrm{~g})$. Two mothers $(3.8 \%)$ in the intervention group and one mother $(1.7 \%)$ in the control group had infants with high birth weight (above $4000 \mathrm{~g}$ ) with no statistically significant differences found in infant weight at birth between the two groups $(\mathrm{P}>0.05)$.

Furthermore, the current study showed that there were statistically significance relationships between total knowledge scores of gestational diabetes mothers in preeducational program and their age at $(\mathrm{P}=0.05)$; and between knowledge of gestational diabetes mothers' pre-educational program and their educational levels at $(\mathrm{P}=0.05)$. This result were confirmed with(El Toony et al., 2018) ${ }^{(18)}$ who studied " Assessing the effectiveness of an educational program for patients with gestational diabetes in Assiut University" and reported that health education plays an important role in increasing patients awareness regarding the GDM risk and its proper management in order to reduce its complications both for the mother and the fetus.

The current study founded that statistically significance relationship between knowledge of gestational diabetic women with their random blood glucose level in pre and post 3 months $(\mathrm{P}=0.05$ and 0.04 respectively); between knowledge of gestational diabetic women and their BMI in post 3 months $(\mathrm{P}=0.04)$; and between birth weight and their knowledge post 3 months of educational program $(\mathrm{P}=0.03)$. This result were confirmed by(Carolan-Olah \& Sayakhot, 2019) ${ }^{(2)}$ who studied "A randomized controlled trial of a webbased education intervention for women with gestational diabetes mellitus" and mentioned that there were statistically significant differences for BMI, and glycemic level between pre- and post-intervention $(\mathrm{p}<0.05)$. The BMI of women in the intervention group decreased between pre- and postintervention [ $(28.60 \pm 7.93)$ vs. $(29.60 \pm 8.32), \mathrm{p}<0.001]$ and maternal glycemic levels fell to normal levels postintervention [ $(4.86 \pm 0.42)$ vs. $(8.80 \pm 2.50), \mathrm{p}=0.026]$. This current study finding may be interpreted due to the high level of compliance from the women to the educational program.

\section{Conclusion}

Educational program is an effective way for improving women knowledge regarding gestational diabetes. It was found that level of knowledge scores post-test were significantly higher after the implementation of educational program as compared to their values at pretest;there was statistically significance relationship between pretest knowledge with women age and educational levels. Moreover, there was statistically significance association between knowledge scores of gestational diabetic women with their clinical outcomes (random blood glucose and BMI) pre and post educational program.

\section{Recommendations}

11. Providing educational program for recently diagnosed gestational diabetic women about proper management of GDM that reduce the possibility of prenatal 
complications; future T2DM; and improving clinical outcomes.

12. Applying counseling tips in gestational diabetic women discharge teaching plan to maintain healthy life style and maximum glycemic control prior to a future conception.

13. Develop a special health care unit for gestational diabetic women that motivate them for early diagnosis, nutritional consultation, health education and management of gestational diabetes that may have positive impact on their future health and their babies.

\section{Further researches:}

- Replication of the study on a larger probability sample in different geographical areas in Egypt to figure out the effect of these educational program in improving women knowledge and clinical outcomes.

\section{References}

1) Kleinwechter $\mathrm{H} \&$ Demandt $\mathrm{N}$. Diabetes in pregnancy-type 1/type 2 diabetes mellitus and gestational diabetes mellitus. Deutschemedizinische Wochenschrift (1946) 2016; 141(18): 1296-303.

2) Carolan-Olah $M \&$ Sayakhot $P$. A randomized controlled trial of a web-based education intervention for women with gestational diabetes mellitus. Midwifery 2019; 68: 39-47.

3) Li L.J, Aris I.M, Su L.L, Chong, Y.S, Wong, T.Y, Tan, K.H \& Wang, J.J. Effect of gestational diabetes and hypertensive disorders of pregnancy on postpartum cardiometabolic risk. Endocrine connections 2018; 7(3): 433-42.

4) 4Evergreen health diabetes education. Gestational diabetes health questionnaire, 2017; askDENS@ evergreenhealth.com.

5) Kolivand M, Rahimi M.A, Shariati M, Keramat A\& Emamian M.H. The Effect of Self-care Educational/Training Interventions on the Outcomes of Gestational Diabetes: A Review Article. Iranian journal of public health 2018; 47(12): 1805.

6) Shaw JE, Sicree RA, Zimmet PZ. Global estimates of the prevalence of diabetes for 2010 and 2030. Diabetes Res ClinPract. 2010;87:4-14.

7) Bone R.L. Big Babies:An exploration of gestational diabetes. International journal of Childbirth 2015; 3 (30): 42-5.

8) Hayes S. Using motivational interviewing to encourage women with gestational diabetes mellitus to breastfeed as a method of reducing their risk of type 2 diabetes mellitus. Australian Nursing and Midwifery Journal 2014; 21 (10): 32-35.

9) El-Sagheer G\&Hamdi L. Prevalence and risk factors for gestational diabetes mellitus according to the Diabetes in Pregnancy Study Group India in comparison to International Association of the Diabetes and Pregnancy Study Groups in El-Minya, Egypt. The Egyptian journal of internal medicine2018; 30(3):131-9.
10) Khan, M.H, Khalique N, Ali A, \& Khan R. Impact of behavior change communication among pregnant women regarding knowledge of low birth weight infants' susceptibility to certain morbidities. Annual Review \& Research in Biology 2013; 3(4):350.

11) McLarty C. development of a questionnaire to assess knowledge in women with gestational diabetes. Bachelor of nursing, School of Nursing, Edith Cowan University.1993, 106p.

12) Eunice Kennedy Shriver National Institute of Child Health and Human Development.Managing Gestational Diabetes: A Patient's Guide to a Healthy Pregnancy. US Department of Health and Human Services, 2003, Cited from https://www.nichd.nih.gov/publications/product/211.

13) Turney J. The nurse's guide to understanding gestational diabetes. AMN Healthcare Education Services. 2013.

14) KAISER Permanente. Gestational diabetes screening and treatment guidline. Kaiser Foundation Health Plan of Washington, 2018.

15) American Diabetes Association [ADA]. Standards of medical care in diabetes. Diabetes Care, 2016; 39(1): S1-S112.

Retrieved from:http://care.diabetesjournals.org/content/suppl/20 15/12/21/39.Supplement_1.DC2/2016-Standards-ofCare.pdf.

16) Igbinidu E, Akhigbe $\mathrm{AO} \&$ Akinola RA. Sonographic evaluation of the amniotic fluid index in normal singleton pregnancies in a Nigerianpopulation. IOSR J Dent Med Sc 2013; 2933.

17) Jenum AK, Morkrid K, Sletner L, Vange S, Torper JL, Nakstad B, et al. Impact of ethnicityon gestational diabetes identified with the WHO and the modifiedInternationalAssociation of Diabetes and Pregnancy Study Groups criteria: a populationbasedcohort study. Eur J Endocrinol 2012; 166 (2):317-24.

18) El Toony L.F, Khalifa W.A, \& Ghazaly, O.M. Assessing the effectiveness of an educational program for patients with gestational diabetes in Assiut University. Egyptian Journal of Obesity, Diabetes and Endocrinology2018; 4(1): 17.

19) Bieda J. Perceptions of Risk for the Development of Type 2 Diabetes in African-American Women with Gestational Diabetes, 2009.

20) Dimka, A. Gestational Diabetes Mellitus among College Students, Its Effects on Macrosomia and Risk of Developing Type 2 Diabetes-Monroe College. 2015.

21) Alharthi A.S, Althobaiti K.A \& Alswat K.A. Gestational Diabetes Mellitus Knowledge Assessment among Saudi Women. Open access Macedonian journal of medical sciences2018; 6(8): 1522.

22) Mohammed G.N. Impact of Designed Teaching Program for Pregnant Women with Gestational Diabetes on Maternal outcomes. 2016 